\title{
A novel printing channel design for multi- material extrusion additive manufacturing
}

\author{
Pinar Urhal ${ }^{1, *}$ \\ ${ }^{1}$ University of Manchester, Mechanical, Aerospace and Civil Engineering Department, M13 9PR, \\ United Kingdom
}

\begin{abstract}
Additive manufacturing has a great potential in terms of its capability to produce components with complex geometries and to make multi-material and composite products by combining different materials in a single manufacturing platform. Current trends for the multi-material extrusion additive manufacturing process are categorized by multi-nozzle systems and multi-material inlet systems. In the case of multiple nozzle system, materials are deposited from different nozzles in sequence. On the other hand, in the case of multi-material inlet system, different materials are sent into a mixing tube and deposited as a mixture of materials. In this case, functionally graded parts can be fabricated by changing the volume fraction of two or more materials. Hence, the fabrication of parts with a continuous material supply by varying ratios for the extrusion technologies requires the development of printing heads with suitable printing channels, capable of varying the mixing ratio of different materials. To evaluate the effect of different printing channel designs on the material's flow pattern and the functionally graded material printability, this paper presents a threedimensional transient computational fluid dynamics (CFD) simulation of the two miscible liquid-liquid system in a printing channel. Different geometries and materials are considered
\end{abstract}

\section{Introduction}

Bioprinting describes a novel tissue engineering approach to create cell-laden constructs $[1,2]$. In this approach, additive manufacturing is used to print a bioink formed by a hydrogel containing cells and growth factors [3]. Ideal hydrogels should present relatively low viscosity, a shear-thinning behaviour and good permeability characteristics [4]. A wide range of hydrogels such as alginate, gelatine, pectin have been reported $[5,6]$.

Initially, bioprinting was used to create cell-laden constructs based on a single material and a single cell type (e.g. fibroblasts, keratinocytes, chondrocytes, stem cells) [7]. Advances in the field of additive manufacturing allowed to create multi-material and multi-cellular constructs using multi-head printing systems [8,9]. However, each printing head usually operates with a single bioink.

\footnotetext{
*Corresponding author: pinar.urhal@postgrad.manchester.ac.uk
} 
At the University of Manchester (UK), we are investigating novel printing heads (e.g. coaxial and tri-axial printing heads, multi-material inlet screw-assisted printing heads or multimaterial inlet pressure-assisted printing heads) to allow the fabrication of more biomimetic constructs, functionally graded constructs and tissue interfaces. The use of printing heads based on multi-material inlets, where the different materials are sent into a mixing tube before printing, allows to change the volume fraction of the different material thus creating functionally graded bioinks.

As this system will be used for the printing of low viscous hydrogel or polymer materials, a finite element based computational fluid dynamics (CFD) model was developed to investigate the flow patterns of some printable miscible materials (Alginate-Gelatine Solutions). This study also investigates the effect of inlet positions on the change of initially determined parameters (velocity and pressure) at the output of the printing channels.

\section{Modelling and Simulation}

\subsection{Printing Heads}

In the case of printing heads with multiple material inlets without any additional element (e.g. a screw) to guarantee good mixing conditions before printing, it is important to identify the best configuration (angle between the inlet channels and the mixing channel) to guarantee that. Therefore, three different configurations were considered as shown in Table 1.

Table 1 Geometric characteristics of the printing heads

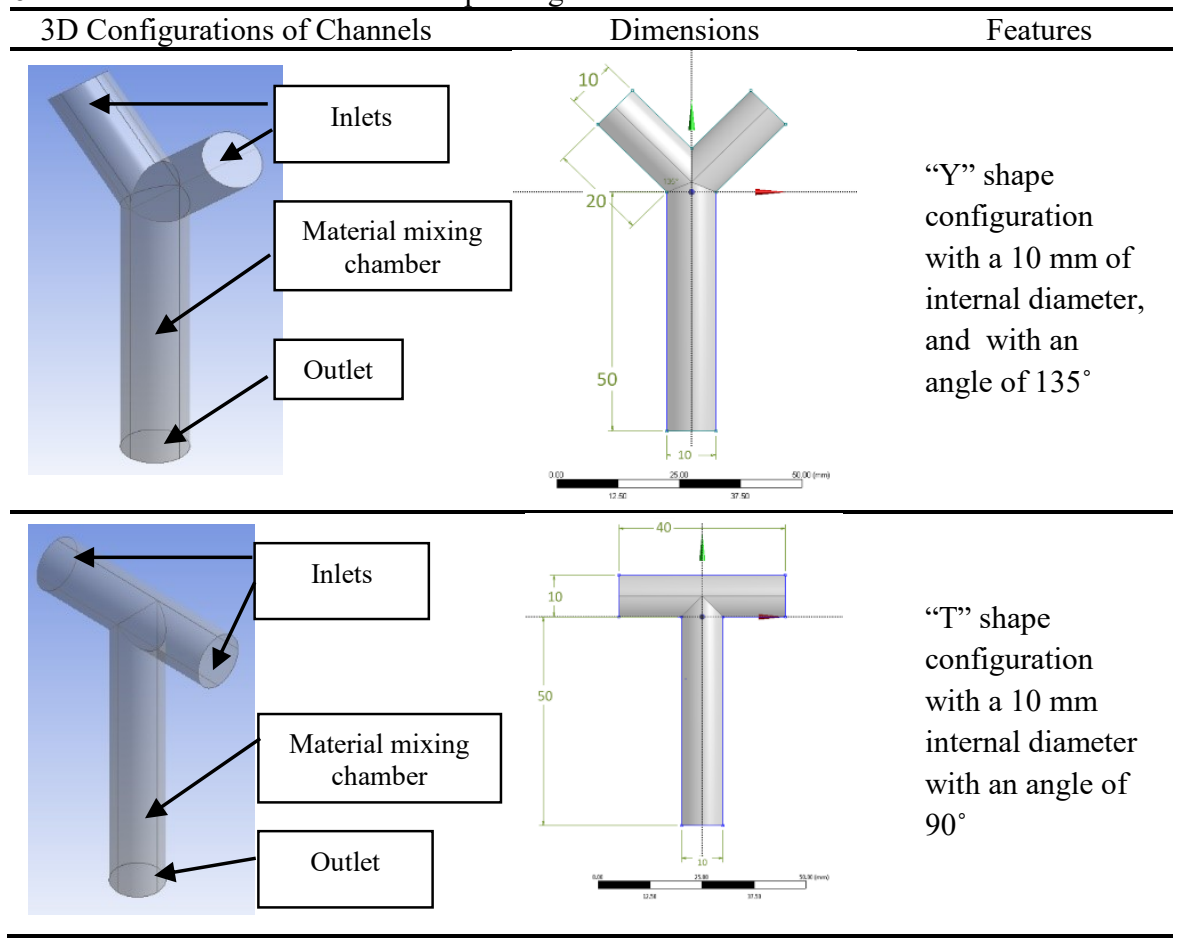


Table 1 (cont.) Geometric characteristics of the printing heads

3D Configurations of Channels 2 Features

\subsection{Simulation Conditions}

Computational Fluids Dynamics (CFD) simulations, were performed using a commercial fluids simulation software (ANSYS, Inc., USA). Printing heads were automatically meshed considering tetrahedral elements and two hydrogels (alginate and gelatine) commonly used for bioprinting applications (see Table 2 for material properties). Based on an extensive literature search the suitable printing concentrations were determined as $2-4 \%$ for sodium alginate and $8 \%$ for gelatine solutions $[10,11]$. For solutions containing $3 \%$ of alginate the extrusion velocity is assumed to be $50 \mathrm{~mm} / \mathrm{s}$, which allows viscous flows with Reynolds numbers ranging between 0.003 and 0.015 , far below the turbulent flow transition boundary.

Table 2 Material Properties

\begin{tabular}{lccc} 
& Solution & Viscosity $(\mathbf{k g} / \mathbf{m . s})$ & Density $\left(\mathbf{g} / \mathbf{c m}^{\mathbf{3}}\right)$ \\
\hline Alginate & $3 \%$ & 0.00925 & 1,256 \\
\hline Gelatine & $8 \%$ & 0.01 & 1.3 \\
\hline
\end{tabular}

The numerical analysis was performed considering the Non-Reactive Multi Species Method, using the species transport equations to evaluate the interaction and volume fraction information of the two considered hydrogels. In the species transport model mixture formulation, the components are mixed at the molecular level and both velocity and temperature are the same for all materials. In order to investigate the effect of the printing channel geometry, all the simulation models were performed under the same boundary conditions (Table 3 ).

Table 3 Boundary Conditions

Inlet 1

Inlet 2

Outlet

\begin{tabular}{lllll}
\hline & & Velocity inlet & Velocity inlet & Pressure outlet \\
\hline Velocity magnitude (m/s) & 0.05 & 0.05 & - \\
\hline $\begin{array}{l}\text { Initial gauge pressure } \\
\text { (KPa) }\end{array}$ & 103 & 103 & - \\
\hline Temperature (K) & 300 & 300 & 300 \\
\hline $\begin{array}{l}\text { Initial species mass } \\
\text { fraction }\end{array}$ & $\begin{array}{l}\text { Gelatine }=0 \\
\text { Alginate }=1\end{array}$ & $\begin{array}{l}\text { Gelatine }=1 \\
\text { Alginate }=0\end{array}$ & $\begin{array}{l}\text { Gelatine }=0 \\
\text { Alginate }=0\end{array}$ \\
\hline
\end{tabular}




\section{Results and Discussion}

Material fractions and mixing ratios of different materials provide relevant information on the suitability of a specific printing head to print functionally gradient materials. Therefore, the influence of the material inlet positions on the material fraction distributions were evaluated by considering the mass fraction contours across the printing channels and outlet cross-sections of those channels.

The material fractions for the gelatine solution (red colour), pumped from the inlet 1, are presented in Figure 1, showing the distribution of the inflowing materials both along the tube and on the outlet. Figure $1 \mathrm{a}$ and $1 \mathrm{~b}$ show that the configurations corresponding to angles of $135^{\circ}$ and $90^{\circ}$ respectively have no effect on the material mixing as it is possible to observe that each material is filling the half of the tube and materials can be identified by the colour gradation of each material's mass fraction values. On the other hand, Figure 1c is presenting different colour gradation behaviour in terms of material mixing. Similarly, it can be seen from the outlet cross-sections of the $45^{\circ}$ inlet position (Figure 1c), the bright red colour for gelatine solution in Figure 1c and for alginate solution is fading into blurred blue and green colours as the fluids flow out from the mixing chamber, which is a clear indication that printing channel with $45^{\circ}$ has a better material mixing performance during the printing process.

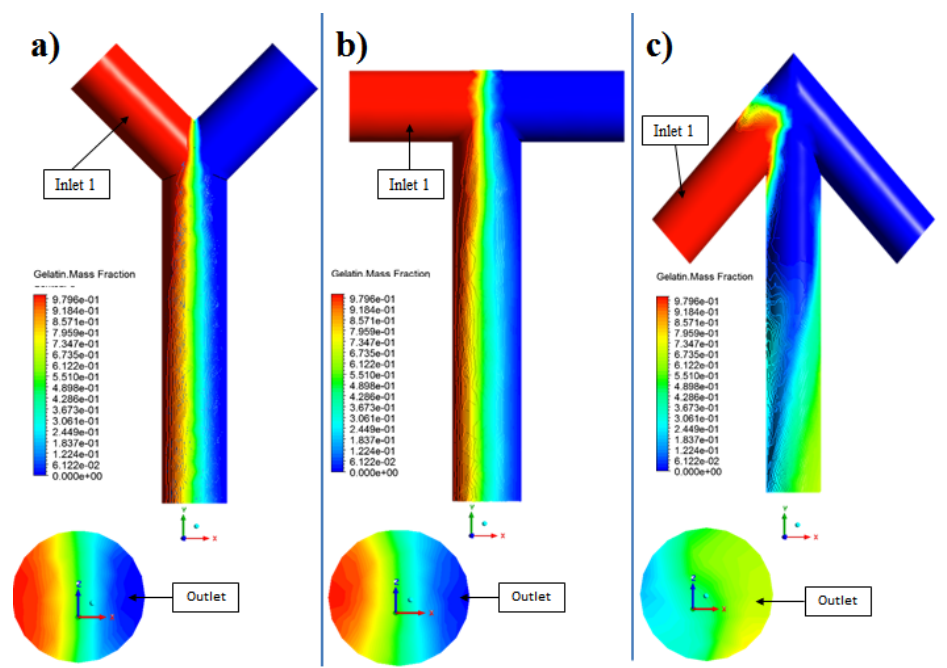

Fig. 1. The volumetric distribution of gelatine solution inside of the printing channels, a) Material inlet angle $135^{\circ}$, b) Material inlet angle $90^{\circ}$, c) Material inlet angle $45^{\circ}$

The effect of the material inlet position on the velocity profile of the fluids along the printing channels is shown in Figure 2. The initial inlet velocities for all configurations was $50 \mathrm{~mm} / \mathrm{s}$. As can be seen from Figure 3, the configurations a and $b$ (Material inlet angle $135^{\circ}$ and Material inlet angle $90^{\circ}$ respectively) show similar velocity profiles, but for the third configuration (Material inlet angle $45^{\circ}$ ), the velocity is reaching its maximum value $(165 \mathrm{~mm} / \mathrm{s})$ at the beginning of the material mixing chamber and decreasing towards the outlet. 


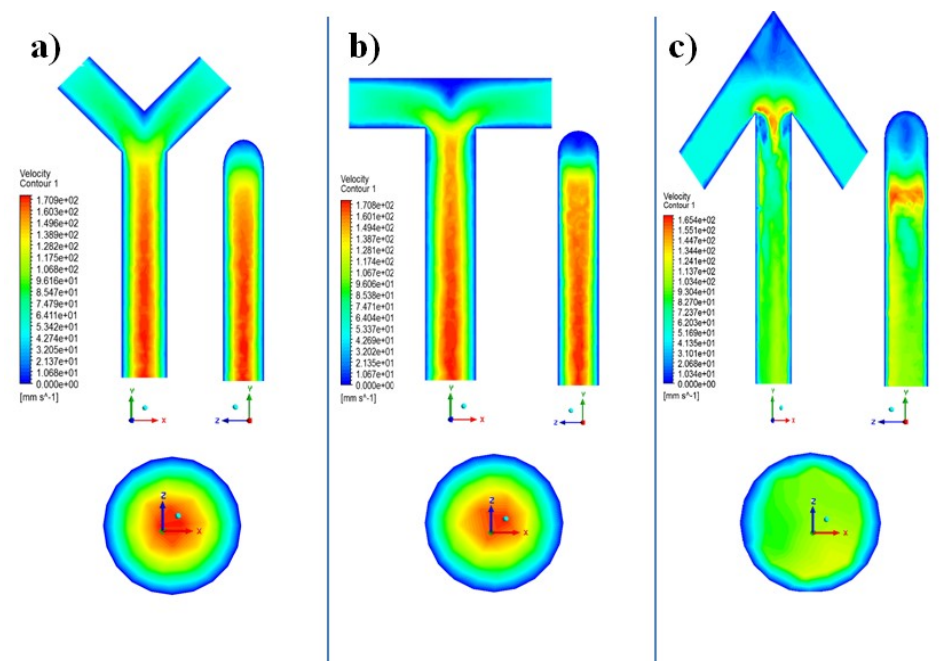

Fig. 2. Velocity contour plots, a) Material inlet angle $135^{\circ}$, b) Material inlet angle $90^{\circ}$, c) Material inlet angle $45^{\circ}$

Finally, the pressure distribution plots for each geometry are presented in the Figure 3.
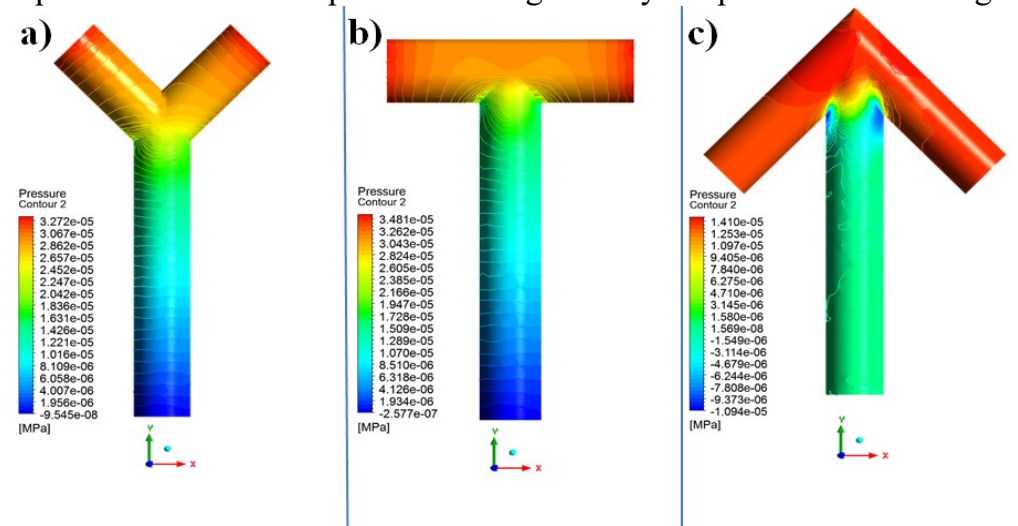

Fig. 3. Pressure distribution plots, a) Material inlet angle $135^{\circ}$, b) Material inlet angle $90^{\circ}$, c) Material inlet angle $45^{\circ}$

\section{Conclusion}

In this study we aimed to investigate the effect of the position and configuration of the inlet of printing channel on the functionally graded material printability. A numerical method was used to determine the flow and mixing behaviours of two miscible biomaterials. Three different printing channels (each with different material inlet angles: $135^{\circ}, 90^{\circ}, 45^{\circ}$ ) were designed. Based on the simulation results, it was possible to observe that the angle of the material inlets has a significant impact on the material mixing rations of materials at the outlet of the printing channel. The highest material mixing performance was observed for the $45^{\circ}$ material inlet printing channel. As mentioned earlier, although screw-assisted extrusion additive manufacturing systems enable better material mixing, the results of this study indicate that functionally graded materials can be additively manufactured by using airassisted extrusion AM method if the suitable material inlet angle is chosen. Moreover, screw- 
assisted systems, contrary to air-assisted extrusion systems, are not suitable to print bioinks (hydrogels containing cells).

\section{References}

1. D.-W. Cho, B. S. Kim, J. Jang, G. Gao, W. Han, N. K. Singh, D.-W. Cho, B. S. Kim, J. Jang, G. Gao, W. Han, and N. K. Singh, in 3D Bioprinting (Springer International Publishing, 2019)

2. S. V Murphy and A. Atala, Nat. Biotechnol. 32, 773 (2014)

3. D.-W. Cho, B. S. Kim, J. Jang, G. Gao, W. Han, N. K. Singh, D.-W. Cho, B. S. Kim, J. Jang, G. Gao, W. Han, and N. K. Singh, in 3D Bioprinting (Springer International Publishing, 2019),

4. A. Subash, B. Kandasubramanian -Rushikesh, S. Ambekar, B. Kandasubramanian, and P. Rastogi, (2019)

5. M. Hospodiuk, M. Dey, D. Sosnoski, and I. T. Ozbolat, Biotechnol. Adv. 35, 217 (2017)

6. J. Li, C. Wu, P. K. Chu, and M. Gelinsky, Mater. Sci. Eng. R Reports 140, 100543 (2020)

7. F. You, X. Wu, N. Zhu, M. Lei, B. F. Eames, and X. Chen, ACS Biomater. Sci. Eng. 2, 1200 (2016)

8. M. Toursangsaraki, Comput. Sci. Phys. (2018)

9. C. De Maria, G. Vozzi, and L. Moroni, MRS Bull. 42, 578 (2017)

10. Y. He, F. Yang, H. Zhao, Q. Gao, B. Xia, and J. Fu, Sci. Rep. 6, 29977 (2016)

11. M. Di Giuseppe, N. Law, B. Webb, R. A. Macrae, L. J. Liew, T. B. Sercombe, R. J. Dilley, and B. J. Doyle, J. Mech. Behav. Biomed. Mater. 79, 150 (2018) 